\title{
A NOTE ON THE DERBYSHIRE SANATORIUM.
}

\author{
BY SIDNEY BARWISE, \\ M.D., B.SC., \\ County Medical Officer of Health for Derbyshire.
}

IN the past sanatoria have been erected in surroundings and on sites which, although ideal, are widely different from those to which the working-class patient must revert when the period of treatment is concluded. The result is that, although he may do very well in such an institution, on his return home he is depressed and disheartened by the great change, and comes to regard as an impossible ideal any attempt to remodel his domestic life on sanatorium lines. Bearing all this in mind, the Derbyshire County Council have erected their sanatorium on the outskirts of: Chesterfield, a mile and a half from the centre of the town. "The site slopes to the south, and is about 400 feet above Ordnance Datum. On admission the patient is placed in a single-bedded ward, where the open window space can be regulated, and in winter the apartment may be heated. He is next removed to a double-bedded ward, with no heating and less completely protected from winds. Finally he is allowed a place in the open-air pavilions. It is intended subsequently to provide open-air shelters similar to those available for home use, in which he may be taught to live before leaving.

The sanatorium consists of two pavilions; each containing fifty beds, one for males and one for females. . Each pavilion has its own diningroom, with twenty-five beds arranged on each side of it. A doctor's house, an administrative block, and a nurses' home, are also provided. The administrative block is built in the shape of the letter $T$. The top part of the $T$ consists of a single row of rooms occupied by the nurses; the stem of the $T$ is occupied by the domestic staff, while the junction of the horizontal and vertical limbs has, only one story, it being a kitchen. In this way no smell of cooking enters the building. There is a detached laundry and steam disinfectory', and there are two workshops, one for males and one for females. The special points of the sanatorium are(I) The concrete floors throughout the patients'. pavilions; (2) the absence of any attempt to heat the open-air pavilions; (3) the system of heating the open-air dining-rooms by means of a slightly, warmed floor. To heat the dining-rooms the hot-water pipes have been enclosed under a concrete floor. The result of this is that the whole of the concrete gradually becomes warm up to a temperature of about $60^{\circ}$, and every unit of heat is utilized. The scheme is a great success. One essential for its adoption is that the floor must be above the level of the 
A NOTE ON THE DERBYSHIRE SANATORIUM I27

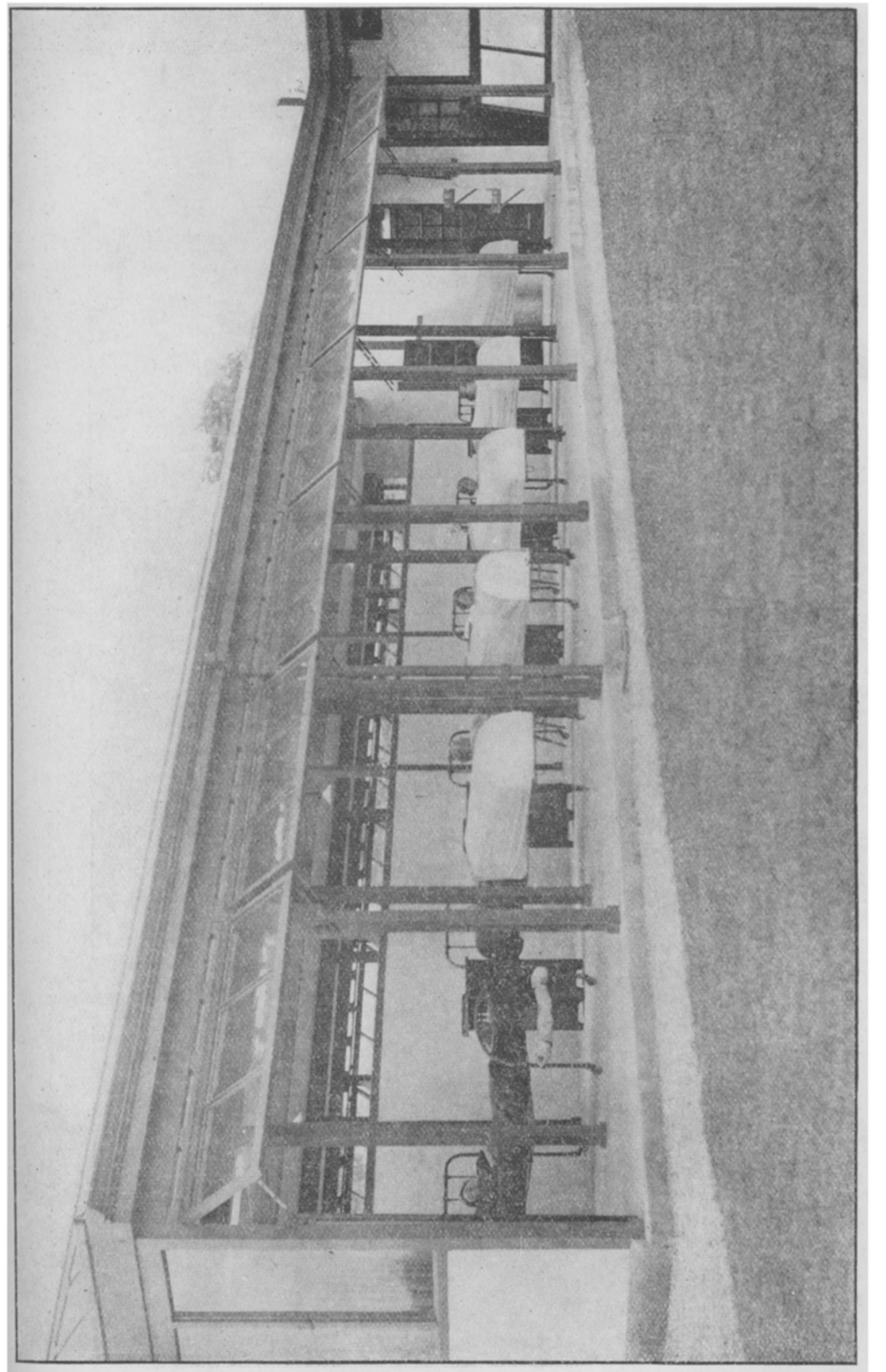

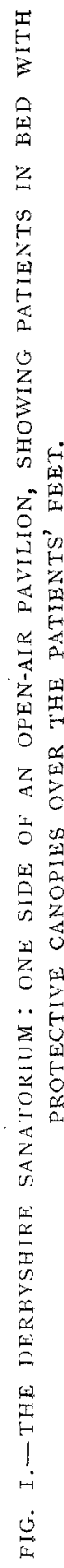


I28 THE BRITISH JOURNAL OF TUBERCULOSIS

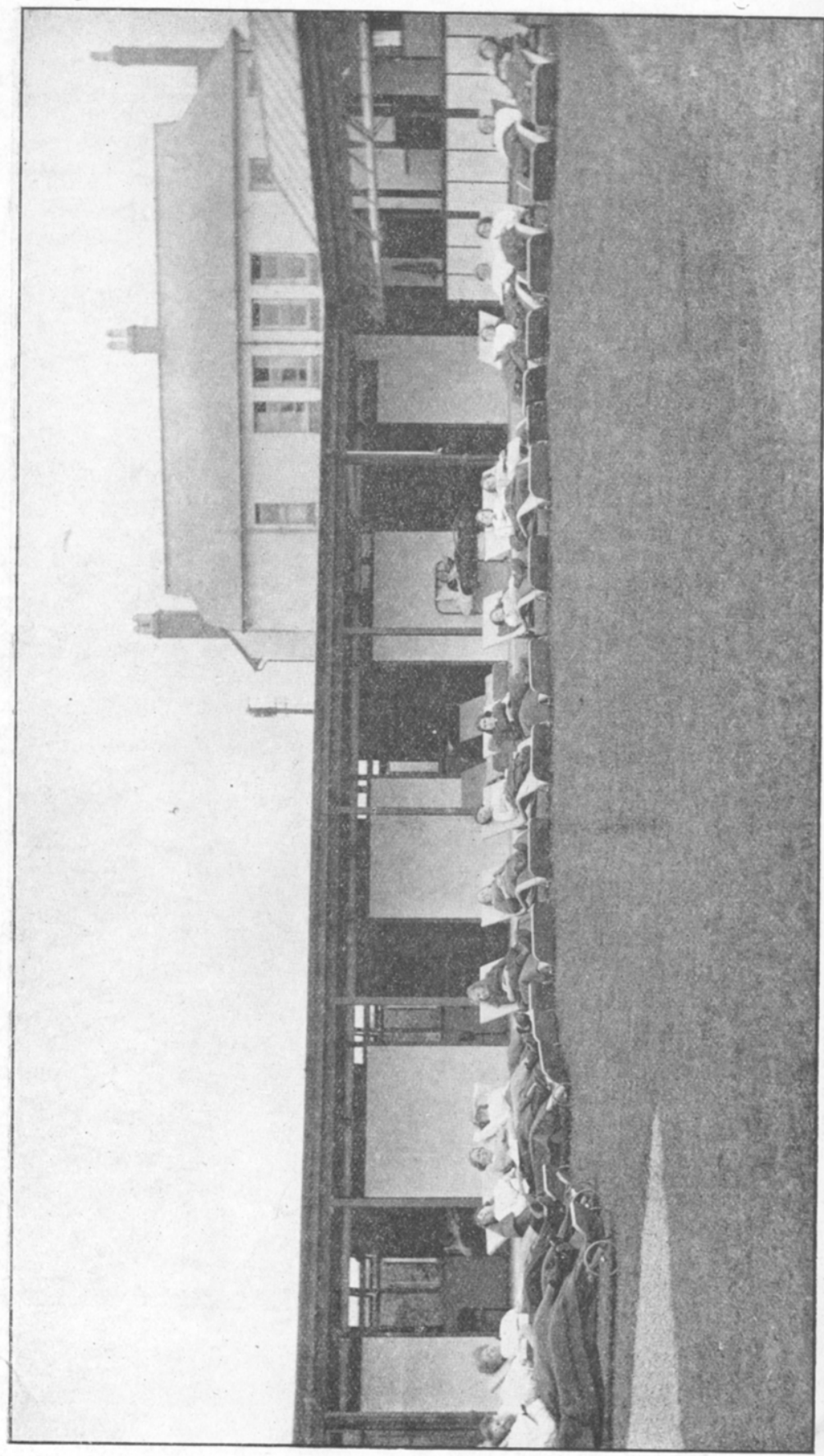

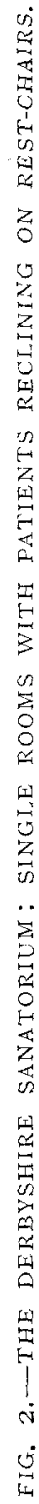


A NOTE ON THE DERBYSHIRE SANATORIUM I29
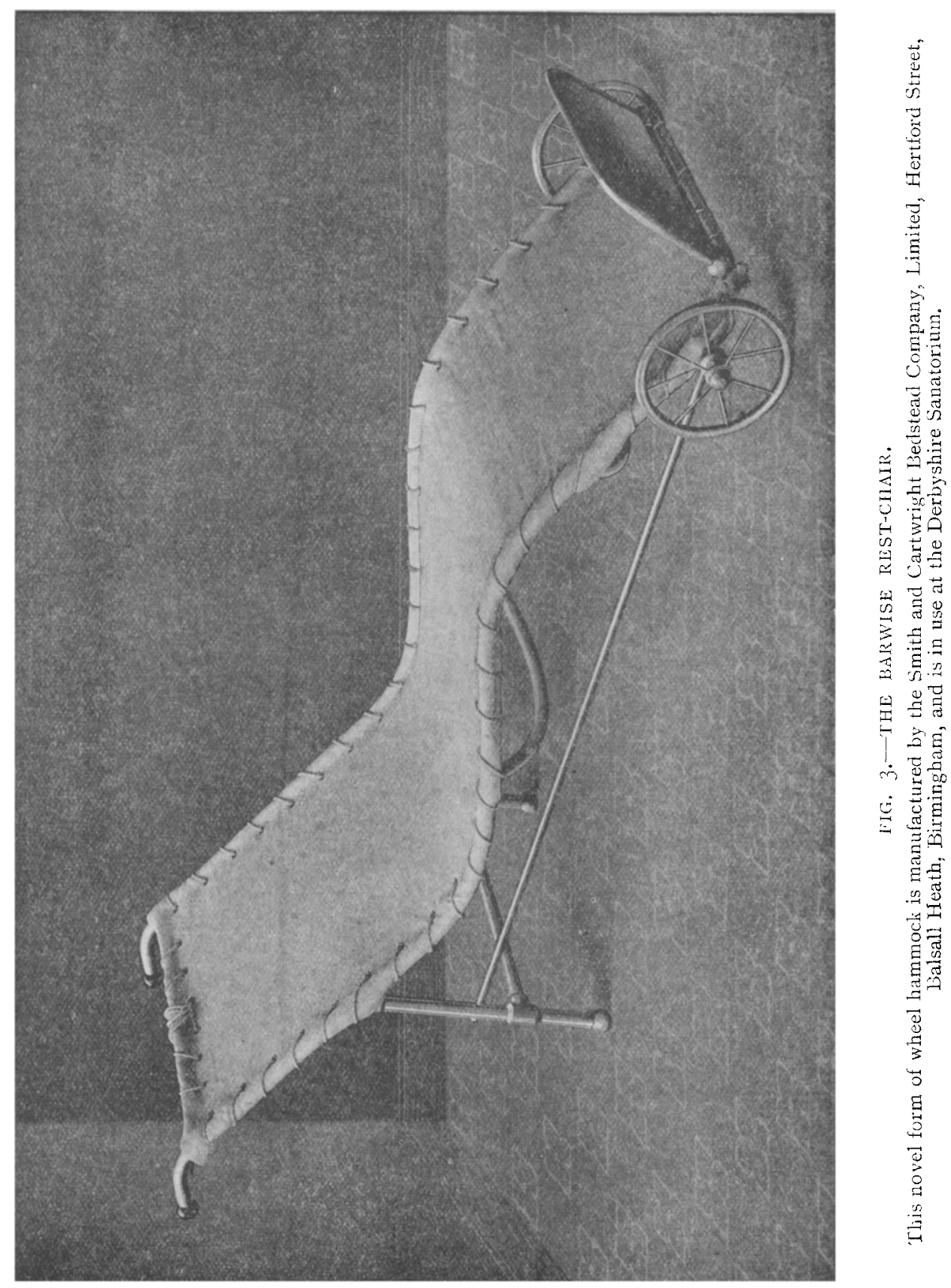
I30 THE BRITISH JOURNAL OF TUBERCULOSIS
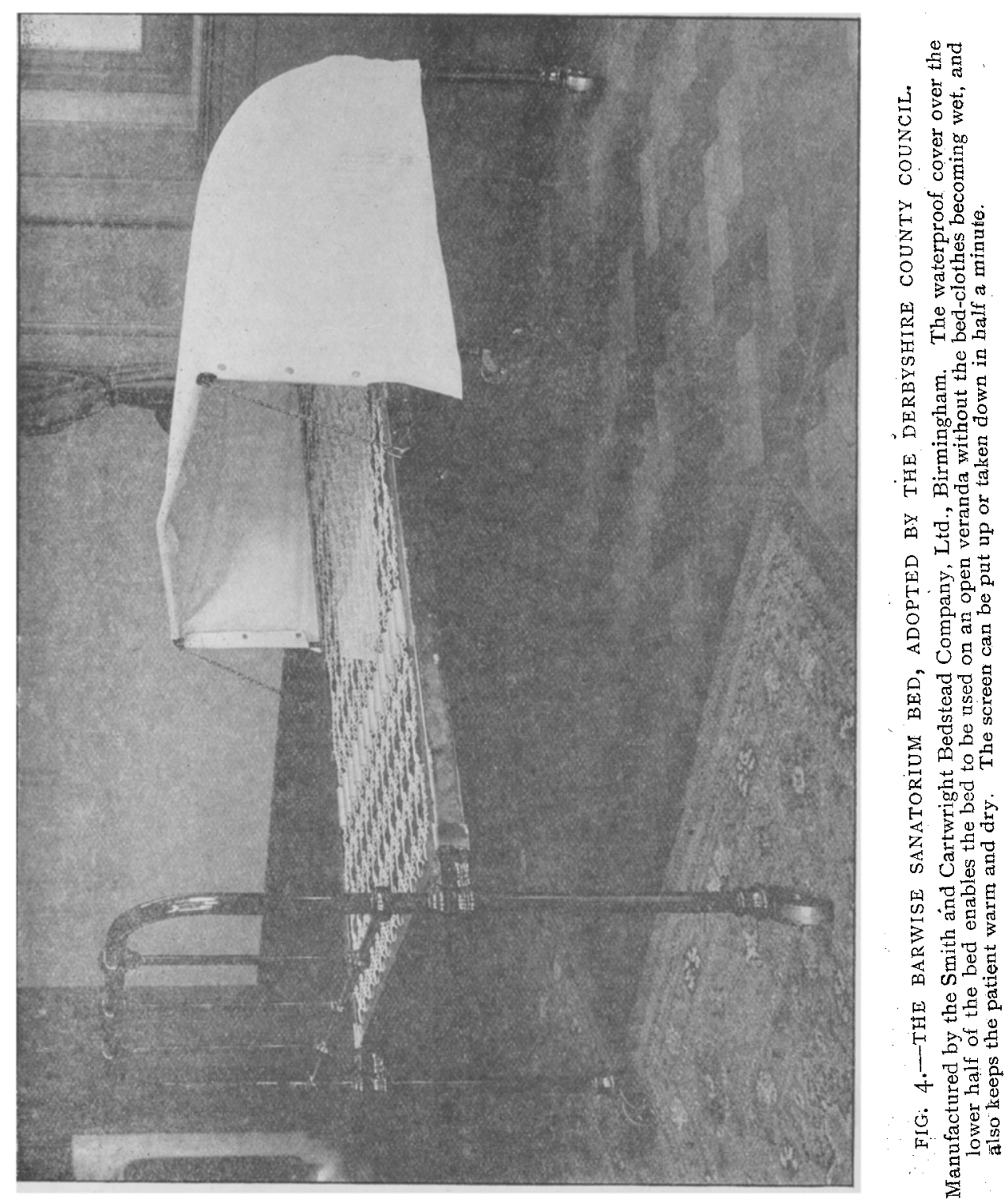


\section{A NOTE ON THE DERBYSHIRE SANATORIUM I3I}

ground, and there must be no subsoil water, otherwise the heat would be wasted in its evaporation. Fig. I shows one of the open-air pavilions with the patients in their beds, with protective canopies over their feet. These bed-canopies are lifted over the bottom half of the beds, and keep the patients dry and warm in the severest weather. They were employed through the whole of the past winter, and the patients who used them stated that the canopies were better than two hot-water bottles. When not required, the sides of the canopy are pulled out, the arms folded in, and the canopy rolled up and placed in the rest at the bottom of the bed.

The patients have been provided with rest-chairs on wheels. These are easily moved about, and are practically lateral suspension hammocks, the sides being bent at such an angle as to give the greatest comfort and rest. In Fig. 2 a number of the female patients are seen reclining, in the rest-chairs in front of the single rooms, while Fig. 3 shows one of the rest-chairs in detail. The canvas, as will be noted, can be easily removed for washing and disinfecting. Both the canopy-beds and the rest-chairs have been patented, and are made by the Smith-Cartwright Bedstead Company, of Birmingham. The details of the canopy-bed are shown in Fig. 4.

The total cost of the sanatorium, including land, furnishing, and equipment, was nearly $£ 22,000$, or $£ 220$ per bed. The buildings themselves cost $\mathscr{E}$ I2O per bed. The whole building reflects the greatest credit on the architects, Messrs. W. H. Ward, of Birmingham. It is one of the cheapest sanatoria yet erected, and at the same time I think it is in advance of any sanatorium I have seen. 